\title{
The Impact of Microcredit Program on Cambodia
}

\author{
Author: Jingcheng Song ${ }^{1}$ \\ ${ }^{1}$ Shanghai Star-river Bilingual School
}

\begin{abstract}
In order to explore the present development of Microcredit, the actual value to natives and future challenges microcredit faces in Cambodia, survey data, qualitative researches, and field experience have been utilized. The present stage and recent development of Microcredit in Cambodia were analyzed based on the survey data and statistical data. Throughout the research, I went to Cambodia and interviewed Cambodians about their real reflection under the local microcredit program. Survey data reveal that the usage of Microcredit in Cambodia has increased rapidly and continued to have a steady upward trend. Through the personal interview, we can find a positive reflection about microcredit programs' improvement in native's daily lives. However, the future development of microcredit organizations will not be plain sailing because the potential problems may emerge over time. Despite the deficiencies in the research process, this paper produces a detailed reflection of Microcredit's impact on Cambodia and its future development, which has essential research significance.
\end{abstract}

\section{Introduction:}

According to the world bank, there are approximately 25 billion people who cannot access financial support from formal financial institutions (ex. Bank), and eighty percent of them are under the poverty line. Microcredit, which can provide necessary funds at the bottom of the pyramid, is essential to these people. Many Southeast Asia countries are now seeing a boom in Microcredit, especially Cambodia. The active number of borrowers in Microcredit has increased fourteen million people from 1999 to 2014 in Cambodia. Increasing usage of Microcredit can sufficiently promote the development of Pro-poor strategies. After years of war, poverty, famine, and widespread instability, Cambodia is still undergoing reconstruction and recovery. In order to reduce abuse, Microcredit has pioneered a way of releasing poverty and has achieved an irreplaceable position in solving the problems. With the money borrowed from Microcredit, local Cambodians can start their own business, ensure primary healthcare, afford children's education, and even increase women's status. In this paper, I put emphasis on how these microcredit programs work, what exact utility they can bring the natives and the potential challenges in the future development of microcredit programs. The rest parts of the paper will be started from introducing the history and social phenomenon of Cambodia.

\subsection{Recent history of Cambodia:}

A communist organization called Khmer Rouge formed in Cambodia in 1970. In 1975, Khmer Rouge occupied Phnom Penh and established a government that killed about 3 million people, making it a terrorist organization.
Workers on the farm collectives established by Khmer Rouge were suffering from the effects of lack of food and overwork. Thousands of workers died from starvation, diseases, and damage to their bodies. Besides, to keep its govern, Khmer Rouge tortured and executed the educated Cambodians in particular regions. In this way, the supply of younger workers dries up, and technology development ceases. In summary, food production and young labor are remarkably low during this time, and this situation also influences the future economic development of Cambodia.

In addition, it is Cambodia's local custom that people spend money as much as they get. This means that local people in Cambodia do not have an awareness of saving, which is may also a factor of the national economy stuck on a plateau of slow growth.

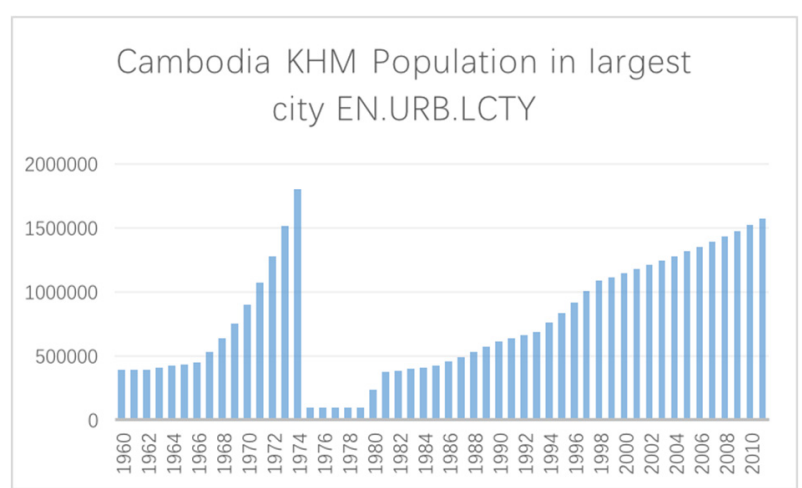

Figure 1. Respondents are all Cambodian in the largest city. $\mathrm{Y}$-axis reports the number of population in the largest city of Cambodia. X-axis reports years from 1960 to 2010. All data sources come form World Development Indicators 1960 to 2010. 


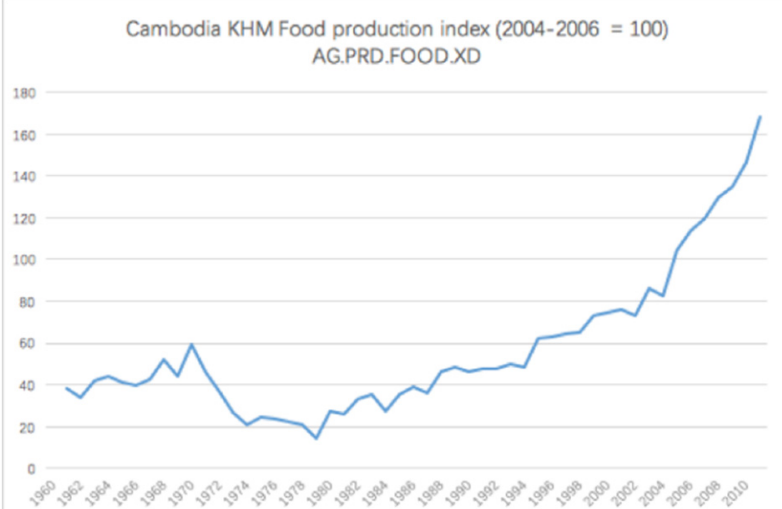

Figure 2. Respondents are all the food production in Cambodia from 1960 to 2010 . Y-axis reports the amount of food production. X-axis reports years from 1960 to 2010. All data sources come form World Bank 1960 to 2010.

\subsection{Social Phenomenon in Cambodia at the present stage:}

Although poverty in Cambodia has been slashed from nearly $50 \%$ to $35 \%$ between the mid- 1990 s to the mid2000 s, there is still a significant number of people under poverty. There is approximately 32 percent of children under 5 in Cambodia stunted. Increasing malnutrition in children is essential for child stunting. Currently, more than $10 \%$ of Cambodian children are unable to go to school or have an education. Since only $20 \%$ of Cambodian girls go to a secondary school, access to education for them is even more restricted. Besides, for many families in Cambodia, parents go out for work and leave children at home, which is dangerous for young kids to confront all the issues at home.

Years of war in Cambodia made male death rate much higher than females, and now about two-thirds of adults are female. Many of them suffer from poor health and receive no education at all. Females shoulder the burden of both work and parenting and with an average of five children per woman. Until recent year women were still often excluded from decision making in many essential programs. Besides, for the food price in Cambodia, while many rural wages have grown at two to three times in the last ten years, the surge in food prices was still higher than many rural' income.

After discussing recent history and social Phenomenon in Cambodia, the next part will be focused on the difference between microcredit and peer to peer lending.

\section{The difference between microcredit and peer to peer lending:}

Compared with Microcredit, peer to peer lending is more widely acknowledged around the world and is commonly shown on the website. There are both similarities and differences between these two programs. Both peer-to-peer lending and Microcredit are being options for people whom the banks are not willing to loan to. However, Peer-to-Peer Lending is a Loan--not a
Donation. Peer-to-peer lending is considered as debt funding, which means small businesses borrow money from peers on the Internet and pay the capital back with interest after a fixed term of years. The interests, most importantly, sometimes are high and risky. One of the significant risks is that borrowers could default on their loans. Therefore, many borrowers are forced to give out many objects away, even their houses. In China, there are countless cases every year about "campus loan," which are strictly related to peer to peer lending. Investors have many ways to threaten young borrowers, and the police rarely catch them.

On the other hand, Microcredit is much milder. It is more likely to be a donation than a loan. Microcredit to the poor is not a new idea. In the book Due Diligence, David Roodman describes the long history of Microcredit, who began to lend small amounts to poor people in the early 18th century. Usually, organizations would offer Microcredit to poor borrowers with no interests. Microcredit's primary purpose is not at making money but helping the poor and developing the local economy. The risk of Microcredit is much lower than the one of peer to peer lending, but the requirements are much higher. Not all the situations can apply for Microcredit, only after interview and determination can a person acquire money.

In summary, Microcredit has a high barrier, low risk, and usually offline. Peer to peer lending has a low barrier, high risk, and usually on the Internet. (Microcredit commonly appears in undeveloped counties, and there is a much lower demand in developed countries.)

After identifying the difference between microcredit and peer-to-peer lending, next part will be mainly focus on microcredit program in Cambodia.

\section{Microcredit in Cambodia:}

Founded in 1991, Khemara is the first and most exceptional Non-Government Organization (NGO) in Cambodia, which works with women and children and offers Microcredit. About 4.5 million people continue to live in a "near poverty" state, which means they are easily falling back into poverty when confronting economic shock. As a result, the purpose of Khemara is to help some small enterprises to establish and develop their businesses, assist the vulnerable local communities to improve their livings, and enhance economic conditions in the long run.

In recent years, the usage rate and average gross loan portfolio of Microcredit in Cambodia and the number of active borrowers have increased rapidly. (As shown below) 
NGO Average gross loan portfolio (Sum)

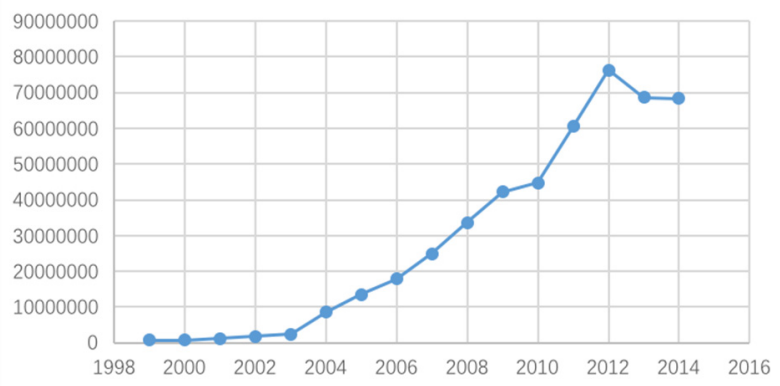

Figure 3. Respondents are the Non-Governmental Organizations from 1998 to 2014 in Cambodia. Y-axis reports the amount of the average gross loan portfolio. Xaxis reports years from 1998 to 2014. All the data source comes from world bank from 1998 to 2014

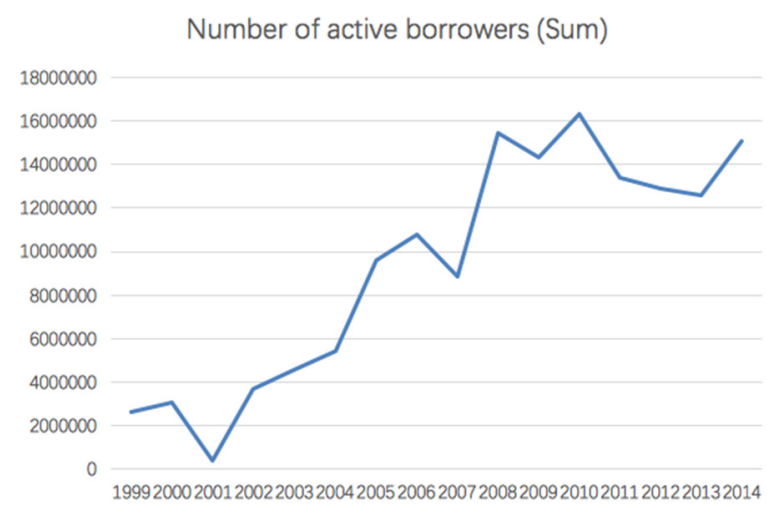

Figure 4. Respondents are the active borrowers from 1999 to 2014 in Cambodia. Y-axis reports the number of active borrowers(sum). X-axis reports years from 1999 to 2014. All the data source comes from world bank from 1999 to 2014

There is a delicate process of Microcredit in Khemara to evaluate whether to lend money to the borrowers. Firstly, natives need to fill a table about some simple personal information and home address to apply for Microcredit. Secondly, staff in Khemara would visit the natives who apply for Microcredit and have a face to face interview. The interview is mainly focused on "Why you apply for microcredit?" "What is your plan for the money?" and "How is your present situation?". After collecting this information, the staff in Khemara will analyze the report. Finally, after the final discussion, the group will decide whether to lend the money or not.

In addition, Khemara does not only lend money to the local people but also cultivate the habit of saving money among local people in the process of Microcredit.

\section{Pre-existing samples of microcredit program:}

I once worked as a volunteer in Khemara during the summer holiday. During that time, I interviewed about ten natives who apply for Microcredit and also visited numbers of local people who are now successfully managing their small businesses after assistance. There are various businesses these people run in Cambodia under the assistance of Khemara and here are some of the businesses I visited during the volunteer work.

1) Fishing: The fisherman who applied for Microcredit was about fifty years old with seven children. In fact, he earns much higher money than average in Cambodia every month. However, when his net was broken, he still had to borrow money from Khemara. The price of a durable net usually costs 60 dollars, which is just half of his monthly income. Because he did not have the habit of saving money, all the money was spent as soon as he got them, and, as a result, he needed to apply for Microcredit to further his business. Khemara lent the money to the fisherman and helped him creating an account to save money. As a result, the fisherman solved the problem and was able to deal with the broken net by himself next time.

2) Childcare center: A family that lives in Phnom Penh applied for Microcredit to establish a child-care center for years. When I visited the center, the crumbling houses described in the previous report had gone, replaced by tidy little classrooms. There are many kids around five years old playing together in the center with laughers. A family could not offer the cost of operating a child-care center at the beginning of the business, so they asked Khemara for help. Luckily, after borrowed enough money from Khemara, they started their business and successfully manage it till now. Sokhorn, the mother in the family, said that Microcredit had dramatically improved her life. She once shouldered a heavy burden of both parenting three kids and working eight hours a day in a factory. Until recently, she could finally enjoy a much more relaxed life than before. In addition, because of the establishment of her child-care center, many parents sent their children to the center to ensure safety. For most of Cambodia, parents spend a considerable amount of time working in the factory, so their children are left alone. It is very dangerous to leave a little kid alone at home, and the child mortality rate in Cambodia is very high. However, when Sokhorn's child-care center was founded, child mortality in the town was reduced for the kids to be noticed much quicker if they were sick in the child-care center than at home alone. The found of child-care center does benefit not only Sokhorn's family, but also the whole community as well.

3) Coffee shop: Kek Srey is one of the youngest girls who applied for Microcredit. She borrowed money from Khemara in her nineteen years old when her family planned to marry her to someone she has never meet. Her family then cut down Kek's financial income because of her rebellion. At this moment, Kek found Khemara and asked for help. In the end, Kek opened a coffee shop with the borrowed money and made money by herself every day. As coffee shops were not so typical in small towns in Cambodia, Kek soon attracted many customers and made money higher than average every month. During the visit, Kek was pleased to answer the questions, and she said that Microcredit not only brought her money but also helped her escape that terrible marriage. Because of the ability to make much money, Kek's status in her family raised, and she was free to choose her own life in the end. 
The three examples of "pre-existing samples of microcredit program" mentioned above may not represent entire aspects of the program. We can still see the excellent enhancement microcredit brought to the local people. In the process of lending money, Microcredit in Cambodia cultivates habits of saving money among natives; Providing local contribution with money, Microcredit improves conditions in surrounding communities; By lending money especially to the ladies, Microcredit even increases women's status in the specific region.

According to this trend continues, from my perspective, Microcredit program should encourage their borrowers to explore more diverse businesses. The money lent by Khemara is quite limited, so I think most of the businesses raised by natives are the primary industry and tertiary industry (the secondary industry is too expansive to start). However, the products produced by the primary and tertiary industries are very elastic, which means the market is highly competitive. If many newly raised businesses are similar to the old ones, it would substantially disperse customers' purchasing power. So the profit of all business owners in this field will be reduced. As a result, I personally suggest Microcredit program in Cambodia develop various businesses based on the excellent works mentioned above.

\section{The future challenge of Non-profit Microcredit program:}

As non-profit organizations like Khemara earn no money, they would face many types of risk. The greatest one is funding shortages. Khemara is mainly financed by donations from local enterprises and wealthy people. A small part of the funding source comes from an individual who usually donates a few hundred dollars. Besides money donation, Khemara also accepts in-kind donations. However, Khemara does not accept an inkind donation from an individual out of Cambodia. As a result, the way of a donation is quite limited and unstable.

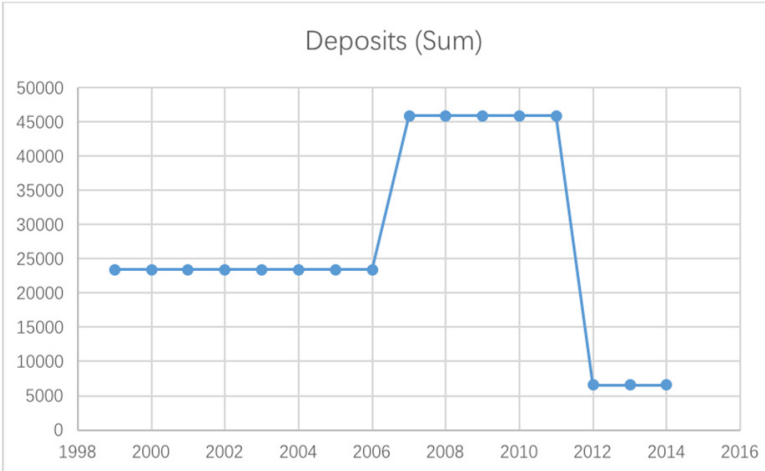

Figure 5. Respondents are the the Non-Governmental Organizations from 1998 to 2016 in Cambodia. Y-axis reports the amount of deposits(sum). X-axis reports years from 1998 to 2016. All the data source comes from world bank from 1998 to 2016.

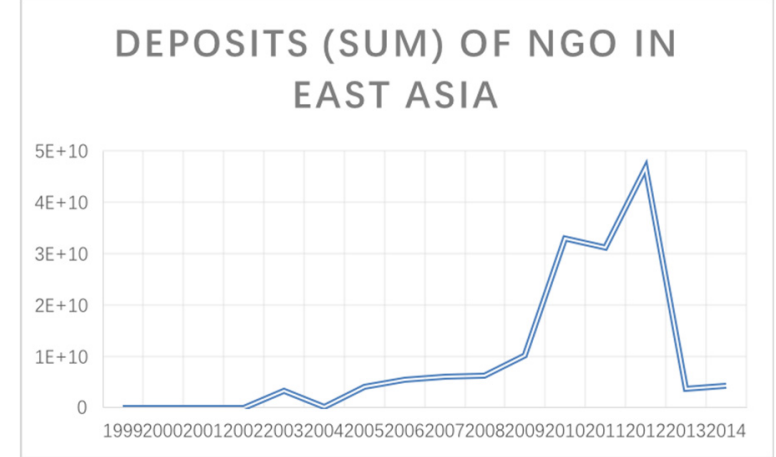

Figure 6. Respondents are the the Non-Governmental Organizations from 1999 to 2014 in East Asil. Y-axis reports the amount of deposits(sum). X-axis reports years from 1999 to 2014. All the data source comes from world bank from 1999 to 2014.

According to the pictures shown above, we can see that the deposits of the organizations are very unable and fluctuating much in recent decades. For the reason that NGOs can't make money for themselves, it is easy for them to face funding shortages. Although most organizations operate on strict budgets, they are still very vulnerable when facing an economic crisis. Because of this reason, some of the non-profit organizations would turn into profit organizations when the economic crisis comes. For example, some microcredit organizations would increase their interest and even have consumer discrimination. However, in this way, the basic principle of these organizations would be broken. In summary, unable to self-sufficiency is one of the most significant challenges for Khemara and other non-profit organizations.

Secondly, theft of funds would also be a challenge for the future development of the organizations. Although the borrowed money for each individual is not much for this is Microcredit, theft of funds would lay the potential danger. For example, if there is an increasing number of thieves recently (even the total number is not much), the organizations would meet a higher standard to their proposers. If the organization higher their standard, it would occasionally refuse someone who needs help. As a result, these non-profit organizations cannot fully be functioning over time.

Thirdly, reputation should also be an essential consideration for the microcredit program. If the reputation for the organization is not well enough, donators will not likely donate. For the simple reason that fundraising fraud is quite common these days, donors would easily have suspicion on this organization and, therefore, choose other projects to donate. On the other hand, local people would prefer organizations with a higher reputation even they may spend more. Actually, it is quite difficult for an organization to keep an excellent reputation for a sufficient period. However, the loss of reputation would consequently result in a loss of both consumers and donators, which is a kind of chain reaction.

According to Khemara's current trend, we can have an assumption of future Khemara's development. On the basis of accumulated fame among Cambodia natives, Khemara's reputation is an advantage instead of a 
challenging point. From my opinion, unlike banks which mainly evaluates one's repaying capability, Khemara focus on evaluating one' overall ability, such as integrity. As a result, if thieves of founds emerge, Khemara will higher its standard and some people who really need help may be refused. This will cause a chain effect: strict standard cause negative reputation, and negative reputation cause reduced amount of borrowers and donators.

Comparing with long-term challenges, short-term challenges cannot be ignored as well. For instance, the unexpected arrival of COVID-19 this year gives the whole market a great shock, and many businesses fail to overcome this crisis. From my perspective, for the Microcredit program in Non-Governmental Organization like Khemara, COVID-19 brings challenges not only to Khemara organization itself but also to its customers' small businesses. Under the widespread of COVID-19, small businesses in tertiary industries face the most significant obstacle. In a country of relatively low purchasing power, COVID-19 further limits the currency circulation. As a result, the small businesses raised by Khemara's Microcredit program may become impoverished, and natives who just borrowed money and raised their businesses may fail to pay back the credits. In addition, this emergency could course a chain reaction. As shown in the pictures above, the deposits in NGOs like Khemara are not optimistic these years, and the economic crisis caused by COVID-19 will make this even worse. An increasing number of borrowing and the decreasing ability to repay would soon threaten the whole Khemara organization. Plus, during this time, the most donation goes for COVID-19, so there is a sharp decrease in the amount of Khemara's donation. Suffering from number of difficulties, Khemara is now facing a significant challenge.

Challenges towards non-profit microcredit programs are including but not limited to the three problems and cases mentioned above. Microcredit programs still have a long way to go.

\section{Conclusions:}

In summary, this paper shows the exact impact of Microcredit on Cambodia based on survey data, qualitative research, and field experience. This paper collects data in the last twenty years, reflecting the development and impact of microcredit programs in various angles. I identified that the usage of Microcredit has been climbing these years steadily, and this program gets favorable responses from natives. The findings in this paper indicate that Microcredit boosts the local economy and improves Cambodian's daily lives. This program benefit neighborhood through building Childcare centers. From an individual prospect, Microcredit helps individuals leave poverty and raise female status. There are many challenges in the future microcredit program attempts to overcome, including funding shortages, theft of funds, and reputation declination. I also analyze the chain influence on Microcredit programs under the recent COVID-19 situation, including impact, development, and opportunity. Through the specific case in Cambodia, we can see the effect of microcredit programs on other undeveloped countries are uncountable and worth spreading.

\section{References:}

\section{Website:}

1. https://www.history.com/topics/cold-war/the-khmerrouge

2. https://borgenproject.org/top-10-facts-aboutpoverty-in-cambodia/

3. https://www.poverties.org/blog/poverty-in-cambodia

4. Cambodia's Silk Road to Poverty Reduction, MarieClaude Frauenrath, International Trade Forum, 2006

5. https://www.humanium.org/en/cambodia/

6. https://www.phnompenhpost.com/national/womensstatus-cambodia? https://thelendingmag.com/whatsthe-difference-between-peer-to-peer-lendingcrowdfunding/

7. https://www.vox.com/futureperfect/2019/1/15/18182167/microcreditmicrofinance-poverty-grameen-bank-yunus

8. https://www.projects-abroad.com.au/volunteercambodia/arrival-procedures/

9. http://www.khemaracambodia.org

10. https://nonprofithub.org/resources/a-nonprofitsguide-to-risk-management/

11. KHMER ROUGE - tititudorancea.org. https://www.tititudorancea.org/z/khmer_rouge.htm

12. About Us - Khemara Cambodia. http://www.khemaraca mbodia.org/ 